\title{
THE FREQUENT BURSTING OF HOT WATER PIPES IN HOUSEHOLD PLUMBING SYSTEMS.
}

By F. C. BRown.

$\mathrm{IT}^{\mathrm{T}}$ seems to have been a common observation by plumbers that the pipes carrying the hot water from the furnace to the kitchen and bath room burst from freezing more frequently than do the pipes carrying the cold water. It is said that the ratio of frequency is at least four to one. The "cold water" usually freezes so as to lessen the flow of water in the pipes or to stop it entirely, but this freezing is seldom accompanied by bursting. If a long connection of pipe falls below the freezing temperature the probability of bursting is enhanced by virtue of its length. The bursting of the cold-water pipes is generally expected when the freezing temperature is very low. That "hot water" pipes should burst more readily than those carrying cold water might appear anomalous. Thus the experiments described in this paper were undertaken first to verify the observations of the plumbers and then to ascertain the physical explanation.

In the experiments an exact duplication of the conditions in the plumbing system were not obtained, but they were approached in some essentials by using glass test tubes closed at one end instead of iron pipe. Ordinary tap water freshly drawn was placed in these tubes to simulate the conditions in the cold-water pipes. The same tap water shortly after being boiled was placed in like tubes to simulate the conditions in the hot-water pipes. The glass tubes were satisfactory in that the visible appearances inside the tube offered valuable information as to what was happening in the respective cases. The breaking stress of the glass was materially lower than that of the ordinary. iron pipe, but expected differences from this cause would merely increase the number of tubes bursting in a given time. The ordinary iron pipe that is stopped by freezing may generally be regarded as an open pipe, contrary to the glass tubes used which had one end closed. The closed pipe would have an increased probability of bursting, because of the lessened opportunity for the release of pressure by the escape of water and ice.

The glass tubes seemed to satisfactorily duplicate the conditions of the plumbing system in that the tubes containing the boiled water did 
burst more frequently than those with the unboiled water. In the preliminary trials, test tubes of varying size and number were placed in the open air when the outdoor temperatures were at varying degrees below zero. The time for freezing varied from thirty minutes to four hours. The hot and cold water were placed in alternate tubes side by side. The tubes were usually about one centimeter in diameter. On seven occasions about 50 pairs of tubes were tried. In every test the tubes of boiled water broke first. When the observations were concluded it was noted that 44 tubes containing boiled water had burst and only four of those filled with unboiled water had broken. For one reason or another slightly more than half of the tubes did not break, even though all the water seemed to be frozen. Having verified the observations of the plumbers with the altered conditions, the next step was to obtain the explanation. The rate of cooling and the temperature at which freezing occurred furnished information that limited the possible explanations. In this experiment both kinds of water were allowed to reach approximate room temperatures before placement in the freezing surroundings outside.

It was found that the boiled water was invariably undercooled several degrees below zero before freezing commenced and that after crystallization began the temperature remained at zero until the entire mass was frozen. The ice was quite clear and solid. The unboiled water always began freezing at zero and the ice was full of air bubbles and appeared quite slushy, particularly near the central axis of the tube. These observations are quite in accordance with the well-known differences existing between the freezing of air-free water and water saturated with air. H. T. Barnes ${ }^{1}$ states that the more the air and ice are mixed the less can the mixture be cooled below zero. When chilled air was passed through the water he obtained frazil or slush ice, lacking in solid structure. He further states that "with agitation, and the presence of dust or suspended matter, and particularly with dissolved air in the water, super-cooling without ice forming may be said to be impossible." Thus the observed differences between the freezing of boiled and unboiled tap water are such as can be explained by the presence or absence of dissolved air. The white spongy ice core along the central axis of the tubes in our experiments approaches in a small way the properties of frazil ice.

The fact that the temperature of the tap water during freezing did not fall below zero is indicative that the impurities, such as dissolved salts, were comparatively small. The explanation then seemed rather

\footnotetext{
1 Ice Formation, published by Wiley, I906.
} 
to involve the super-cooling of the boiled water and the more solid ice formed in it. Both of these are largely dependent on the diminished amount of air in the boiled water:

The ice formed from the boiled water was clear without a decided central region often observed in artificial ice, while the ice formed from tap water was full of air bubbles especially toward the middle. These air bubbles together with accompanying impurities form nuclei for crystallization and also act as cushions to react against the expansion of the water by freezing. The air also tends to freeze out toward the middle. It will be shown that this semi-open center acts as a safety valve to relieve the pressure caused by freezing. The undercooling of the air-free water tends to make the center of the tube freeze just as solid as the water near the surface of the tube.

The occluded air also seems to make the ice more fluid in its nature. In 28 tubes side by side, which were alternately filled with boiled and unboiled water, to the same depth in each case, there was observed in every case to be a greater rise of ice in the tubes in which the unboiled water froze. Quantitative heat measurements showed that approximately the same amount of ice was formed in each case. Therefore the ice from the tap water either was less viscous than the other ice or the central core of the tap water ice remained mobile sufficiently long to relieve the pressure by carrying water and ice crystals along the tube to regions of less stress. Koch ${ }^{1}$ found the ice containing air bubbles to have a lower elasticity than air free ice. In other words air bubbles weakens the ice. Quincke ${ }^{2}$ observed when water containing both air and dissolved salts began to freeze that both the air and salts separated out from the ice alike, leaving the mother liquid excessively rich in both air and salts. This explains why the central core in the frozen tap water was particularly full of air bubbles. This central core either remained open or froze into a slushy ice mixture. In either case this formed an easy avenue for the release of the water pressure that tended to exist by virtue of the ice freezing along the outer wall of the tube.

The foregoing conclusion that the air in ordinary tap water is responsible for the non-bursting of cold-water pipes in many instances was further checked as follows. Water that had been boiled was afterward saturated with air by passing a stream of air through it for several minutes. Under these circumstances six pairs of tubes, alternately boiled and unboiled water, burst at about the same time. However the bursting was delayed as compared with air-free water even when the freezing temperature was quite low.

1 Ann. d. Phys., 4I, pp. 709-727, I913.

2 Proc. Roy. Soc. Canada, 3, p. 24, I909. 
A further experiment was made to be certain that the presence of dissolved salts was of no special importance to the observed phenomenon. Distilled water which had been exposed to the air for several days was substituted for the tap water. One of every pair of tubes was filled with this unboiled distilled water. Every alternate tube was filled with the same water after it had been reboiled. As expected the tubes containing the boiled water burst first. A final test was made by saturating this distilled boiled water with air. This procedure caused all the tubes to behave alike in freezing surroundings.

In view of these experiments it has been concluded that the occluded air in ordinary tap water is responsible for the delay or absence of bursting of the pipes. The air and accompanying impurities assist in furnishing nuclei of crystallization, so that the ordinary tap water begins to freeze at zero degree. At the same time the ice formed is more mobile, especially near the middle of the tube, so that until very low temperatures are reached the pressure is released along the middle of the tube by the flow of water and ice. In addition the air bubbles displacing water form cushions which relieve the pressure on the tube to a certain extent.

The writer is indebted to Mr. Waldemar Noll for very able assistance, particularly in connection with the experimental work here described. 